\title{
Effect of Wetland Reclamation on Soil Aggregates Content and Soil Organic Carbon Distribution of Aggregates in Peat Mire Soil around Xingkai Lake in Northeast China
}

\author{
Li-Li HUO ${ }^{1, a}$, Han-Yu HUANG ${ }^{2, b}$ and Yi AN ${ }^{1, c,{ }^{*}}$ \\ ${ }^{1}$ Agro-Environmental Protection Institute of Ministry of Agriculture, Tianjin 300191, China \\ ${ }^{2}$ Chemistry and Chemical Engineering College, Anqing Normal University, Anqing, 246000, China \\ ahuoliliforgood@163.com, bhanyu_003@yeah.net, 'family198610@163.com \\ ${ }^{*}$ Corresponding author
}

Keywords: SOC, aggregates, reclamation, wetland, The Sanjiang Plain.

\begin{abstract}
Soil aggregates content, soil organic carbon (SOC) concentration and density in soil aggregates in $0 \sim 5,5 \sim 10,10 \sim 20,20 \sim 30 \mathrm{~cm}$ soil layers in peat mire soil in wetland, soybean and paddy field reclaimed from the wetland around Xingkai Lake were determined to investigate how reclamation of wetland for soybean and rice farming impacts soil aggregates content and SOC distribution of aggregates. After reclamation, $>1 \mathrm{~mm}$ macro-aggregates decreased, $0.25 \sim 1 \mathrm{~mm}$ macro-aggregates and micro-aggregates $(0.053 \sim 0.25 \mathrm{~mm}$ and $<0.053 \mathrm{~mm})$ increased. In $0 \sim 5,5 \sim 10$, 10 20, 20 30 cm soil layers $<0.25 \mathrm{~mm}$ micro-aggregates content in soybean field were higher than in paddy filed by $10.18 \%, 11.2 \%, 3.35 \%$ and $13.13 \%$, respectively. Wetland reclamation has reduced SOC concentration of aggregates and soil. SOC concentration in aggregates in soybean field was higher than in paddy field except in $<0.053 \mathrm{~mm}$ micro-aggregates in $0 \sim 5 \mathrm{~cm}$ and $10 \sim 20 \mathrm{~cm}$ soil layers. SOC density in $0 \sim 30 \mathrm{~cm}$ soil layer was ordered from high to low as wetland $>$ soybean field $>$ paddy field. Due to reclamation, SOC density in $<0.25 \mathrm{~mm}$ micro-aggregates in the four soil layers and its share in total soil SOC increased, and that in soybean field was higher than in paddy field. More SOC was allocated into $<0.25 \mathrm{~mm}$ micro-aggregates and might be protected better in soybean field than in paddy field, and reclaim the wetland into soybean field instead of paddy field is more beneficial for the long-term retention of SOC.
\end{abstract}

\section{Introduction}

Soil organic carbon (SOC) is an important source or sink of atmospheric $\mathrm{CO}_{2}$. A slight change in the SOC pool can induce a significant change in the $\mathrm{CO}_{2}$ concentration in the atmosphere $[1,2]$. The SOC pool was heterogeneous, including labile carbon with short turnover time and stable carbon with long turnover time $[3,4]$. The labile pool was sensitive to climate change and human activity, and determined SOC circulation. The stable pool can control and maintain SOC as long-term sink of atmosphere $\mathrm{CO}_{2}$, which played an important role in maintaining SOC for a long time and mitigating climate change $[5,6]$. The physical protection of soil aggregates is the important mechanisms of SOC stabilization [7]. There was more labile newly formed SOC in macro-aggregates $(>0.25 \mathrm{~mm})$ than in micro-aggregates $(<0.25 \mathrm{~mm})$, SOC content followed an increase trend with aggregate size increase $[8,9]$. Increase of SOC by vegetation restoration or fertilization treatments first enriched to large aggregates [10,11], Macro-aggregates contained more initial unstable new SOC than micro-aggregates [9]. SOC in macro-aggregates decomposed more quickly, that in micro-aggregates can reserve for a long time [12]. Micro-aggregates provided better protection to SOC than macro-aggregates [13,14].

The Sanjiang Plain is the largest distribution area of freshwater wetland in China, and the very important SOC pool in north China. SOC density was very high in peat mire soil, and bottomland around the Xingkai Lake was the main distribution area of peat mire soil [15]. Xingkai Lake Farm was constructed in 1955 and wetland had been changed to farmland, which had changed carbon cycle 
model and influenced wetland SOC pool. After reclamation, in the first 5 to 7 years, SOC decreased quickly; then in 15 to 20years, SOC tended to be stable [16]. In this study, wetland, soybean and paddy field reclaimed from the wetland around Xingkai Lake with a long reclamation period were chose as research plots, SOC in micro-aggregates indicated stability of SOC. Soil aggregates content, SOC concentration and density in soil aggregates were determined to investigate how reclamation of wetland for soybean and rice farming impacts soil aggregates content and SOC distribution of aggregates, and ascertain the changes of physical protection of soil aggregates to SOC before and after reclamation. Research results would enrich the carbon cycle research in Sanjiang Plain, and provide support to accurately estimate SOC pool under dramatic land use change, provide scientific basis to optimize regional land use structure in the case of a balance between carbon emission reduction and food production.

\section{Materials and Methods}

\section{Study Area}

Study sites are located at the Xingkai Lake Wetland Experimental Station, Chinese Academy of Sciences $\left(132^{\circ} 20^{\prime} 00^{\prime \prime} \mathrm{E}, 45^{\circ} 21^{\prime} 55^{\prime \prime} \mathrm{N}\right)$. This station belongs to temperate continental monsoon climate and the humid and subhumid regions, experiences a mean annual temperature of $3.1^{\circ} \mathrm{Cand}$ a mean annual precipitation of $750 \mathrm{~mm}$, which is concentrated in summer and accounts for about $70 \%$ of the precipitation throughout a whole year. The coldest month was January with temperature of $-19.2^{\circ} \mathrm{C}$ and the warmest was July with $21.2^{\circ} \mathrm{C}$. There are a lot of snowstorms in winter and freeze-up period is from November to the following March. There are natural wetlands with typical plant Glyceria spiculosa and soybean (Giycine max) and paddy (Oryza sativa) fields reclaimed from wetland. Giycine max and Oryza sativa were both continuously cropped once a year and just litter and stubble was remained. The soybean and paddy fields were ploughed with depth about $20 \mathrm{~cm}$ at the end of the autumn and inorganic NPK fertilizers were used, no organic fertilizer.

\section{Soil Samples Collection and Analysis}

Soil samples were collected from wetland, 50-year-old soybean field and 15-year-old (after 35-year-old soybean field then 15-year-old paddy field) paddy field. Both soybean and paddy fields were reclaimed from wetland. Soil type of all the three adjacent plots is peat mire soil. Prior to planting, as well as after harvesting crop, five sampling sites were selected from on each plot and were arranged in an "S" type layout, and the soil samples at the depths of 0 5, 5 10, 10 20 and 20 30 cm were collected from the soil profile of wetland, soybean and paddy field. The soil samples were stored in the hard boxes and then sent to the lab. The collision was avoided during the transportation to prevent the aggregates from being damaged. When the soil moisture exceeded the plastic limit of the soil, large clots were broken down manually along the natural cleavage planes, passed through a 25-mm sieve, and air dried at room temperature.

Some dry soil samples were ground and passed through a 100 mesh sieve to determine the SCO concentration. While some soil samples were prepared for aggregates isolation using a wet-sieve method. When applying this method, $25 \mathrm{~g}$ air-dried soil samples without impurities (i.e. grass roots) was measured using quartering method. The $25 \mathrm{~g}$ purified soil samples were gently placed on the top of the sieve set $(1.0,0.25$ and $0.053 \mathrm{~mm})$ of an aggregate analyzer, with the top sieve immersed in water. After 10-minute soaking, the soil samples were sieved in the sieve set for 2 minutes with the amplitude of $30 \mathrm{~mm}$ (the sieves were all immersed in water during the whole process). Different sized aggregates were collected respectively from the sieves, dried at $50^{\circ} \mathrm{C}$, weighted, ground and passed through a 100 mesh sieve. The SOC concentration of soil and aggregates were determined by potassium dichromate-external heating method [17] and soil bulk density was measured using cutting-ring method.

The soil horizon $\mathrm{C}$ densities were calculated using the following equation [18]: Horizon $\mathrm{C}$ density $\left(\mathrm{g} \mathrm{C} / \mathrm{m}^{2}\right)=\mathrm{D}\left(\mathrm{g} / \mathrm{cm}^{3}\right) \times \mathrm{C}(\mathrm{g} / \mathrm{kg}) \times \mathrm{T}(\mathrm{cm}) \times 10$ 
Where D is bulk density; C is soil organic carbon content; $\mathrm{T}$ is the thickness of the horizon.

\section{Data Processing}

The data was analyzed using SPSS19.0 software and the figures were constructed using OriginPro8.6.

\section{Results and Analysis}

\section{Effect of Wetland Reclamation on Soil Aggregate Content}

As shown in Table 1, after wetland reclamation, the content of $>1 \mathrm{~mm}$ macro-aggregates was decreased, while the $0.25 \sim 1 \mathrm{~mm}$ macro-aggregates and micro-aggregates $(0.053 \sim 0.25 \mathrm{~mm}$ and < $0.053 \mathrm{~mm}$ ) were increased. Compared with wetland, the $>1 \mathrm{~mm}$ macro-aggregates content in the soil layers of $0 \sim 5,5 \sim 10,10 \sim 20$ and 20 30 cm decreased by 70.15\%, 49.95\%, 42.82\% and 50.73\% in soybean field respectively, and 39.67\%, 38.3\%, $44.42 \%$ and $35.1 \%$ in the paddy field respectively. The content of $0.25 \sim 1 \mathrm{~mm}$ macro-aggregates in the aforementioned four soil layers increased by $37.46 \%$, 29.83\%, $25.18 \%$, and $25.65 \%$ in soybean field respectively, and $17.16 \%, 29.38 \%$, 30.13\%, and $23.14 \%$ in paddy field respectively, comparing to the wetland. Similarly, the contents of $0.053 \sim 0.25 \mathrm{~mm}$ micro-aggregates in four soil layers increased by $12.18 \%$ and $7.0 \%, 4.03 \%$ and $3.13 \%, 1.9 \%$ and $10.37 \%, 9.12 \%$ and $5.5 \%$ in soybean and paddy field, respectively. The content of the $<0.053 \mathrm{~mm}$ micro-aggregates in the four soil layers in soybean and paddy field were elevated by $20.52 \%$ and $15.52 \%, 16.1 \%$ and $5.8 \%, 15.73 \%$ and $3.91 \%, 15.95 \%$ and $6.44 \%$, respectively.

Except for the soil layer of $10 \sim 20 \mathrm{~cm}$, the content of $>1 \mathrm{~mm}$ macro-aggregates in soybean field was higher than that in paddy field, while opposite trend was observed in $0.25 \sim 1 \mathrm{~mm}$ macro-aggregates and $0.053 \sim 0.25 \mathrm{~mm}$ micro-aggregates. Interestingly, the content of the $<0.053 \mathrm{~mm}$ micro-aggregates in soybean field was higher than that in the paddy field at all tested soil layers. After reclamation, the contents of $<0.25 \mathrm{~mm}$ micro-aggregates in soybean field at four soil layers were $32.7 \%, 20.12 \%$, $17.63 \%$ and $25.08 \%$ respectively higher than that in wetland, while that increased by $22.52 \%$, $8.92 \%$, $14.28 \%$ and $11.95 \%$ respectively in paddy field when compared to those in wetland. In addition, the contents of $<0.25 \mathrm{~mm}$ micro-aggregates in four soil layers in soybean field were $10.18 \%, 11.2 \%$, $3.35 \%$ and $13.13 \%$ higher than that of paddy field, respectively (Table 1).

Table1 Aggregates percentage in the soil of wetland, soybean and paddy field

\begin{tabular}{|c|c|c|c|c|c|c|}
\hline \multirow{2}{*}{ Soil layer } & \multirow{2}{*}{ Sample plot } & \multicolumn{5}{|c|}{ Aggregates weight percentage in the soil (\%) } \\
\hline & & $>1 \mathrm{~mm}$ & $0.25 \sim 1 \mathrm{~mm}$ & $0.053 \sim 0.25 \mathrm{~mm}$ & $<0.053 \mathrm{~mm}$ & $<0.25 \mathrm{~mm}$ \\
\hline \multirow{3}{*}{$0 \sim 5 \mathrm{~cm}$} & wetland & $85.85(3.73)$ & $4.32(0.89)$ & $3.80(1.06)$ & $6.03(1.82)$ & 9.83 \\
\hline & soybean field & $15.7(5.15)$ & $41.78(4.93)$ & $15.98(3.98)$ & $26.55(6.10)$ & 42.53 \\
\hline & paddy field & $46.18(1.08)$ & 21.48(4.73) & $10.8(2.65)$ & $21.55(1.00)$ & 32.35 \\
\hline \multirow{3}{*}{$5 \sim 10 \mathrm{~cm}$} & wetland & $75.95(2.54)$ & $7.67(1.03)$ & $6.70(0.95)$ & $9.68(0.56)$ & 16.38 \\
\hline & soybean field & $26(1.65)$ & $37.5(4.90)$ & $10.73(0.78)$ & $25.78(4.03)$ & 36.5 \\
\hline & paddy field & $37.65(4.40)$ & $37.05(8.80)$ & $9.83(1.18)$ & $15.48(5.58)$ & 25.3 \\
\hline \multirow{3}{*}{$10 \sim 20 \mathrm{~cm}$} & wetland & $67.92(2.27)$ & $11.87(1.26)$ & $10.05(0.89)$ & $10.17(0.33)$ & 20.22 \\
\hline & soybean field & 25.1(3.13) & $37.05(2.11)$ & 11.95(0.69) & $25.9(1.26)$ & 37.85 \\
\hline & paddy field & 23.5(10.66) & $42(2.43)$ & $20.42(6.44)$ & $14.08(2.05)$ & 34.5 \\
\hline \multirow{3}{*}{$20 \sim 30 \mathrm{~cm}$} & wetland & $59.88(0.88)$ & $15.78(1.38)$ & $14.38(0.13)$ & $9.98(0.63)$ & 24.35 \\
\hline & soybean field & $9.15(2.10)$ & 41.43(13.13) & $23.5(8.05)$ & 25.93(7.18) & 49.43 \\
\hline & paddy field & $24.78(11.85)$ & 38.92(7.30) & 19.88(6.02) & $16.42(4.88)$ & 36.3 \\
\hline
\end{tabular}

1) The value in the table was the average of three repetition and the value in the brackets was the standard error. 


\section{Effect of Wetland Reclamation on the Soc Concentration In Soil Aggregates}

As shown in Fig.1, SOC concentration decreased after reclamation. Specifically, the SOC concentration decreased in aggregates of all sizes, and the SOC concentration in soybean field was higher than that in paddy field in all sized aggregates other than the $<0.053 \mathrm{~mm}$ micro-aggregates in the soil layers of $0 \sim 5$ and $10 \sim 20 \mathrm{~cm}$.

The SOC concentration in wetland aggregate was reduced with the decreasing particle size, other than those at the soil layers of $10 \sim 20 \mathrm{~cm}$. In soybean field, the order of SOC concentration in different aggregate size classes in $0 \sim 5$ and $20 \sim 30 \mathrm{~cm}$ soil layers was $0.25 \sim 1 \mathrm{~mm}>0.053 \sim 0.25 \mathrm{~mm}>(>1 \mathrm{~mm})>$ ( $<0.053 \mathrm{~mm}$ ), while the orders in 5 10 and 10 20 cm soil layers were $0.053 \sim 0.25 \mathrm{~mm}>0.25 \sim 1 \mathrm{~mm}>$ $(>1 \mathrm{~mm})>(<0.053 \mathrm{~mm})$ and $0.053 \sim 0.25 \mathrm{~mm}>(>1 \mathrm{~mm})>0.25 \sim 1 \mathrm{~mm}>(<0.053 \mathrm{~mm})$, respectively, indicating that the SOC concentration of $<0.053 \mathrm{~mm}$ micro-aggregates was the lowest among the size classes in the four soil layers. Except for the soil layer of $20 \sim 30 \mathrm{~cm}$, the SOC concentration of soil aggregate in paddy field also decreased as the decrease in aggregate sizes.
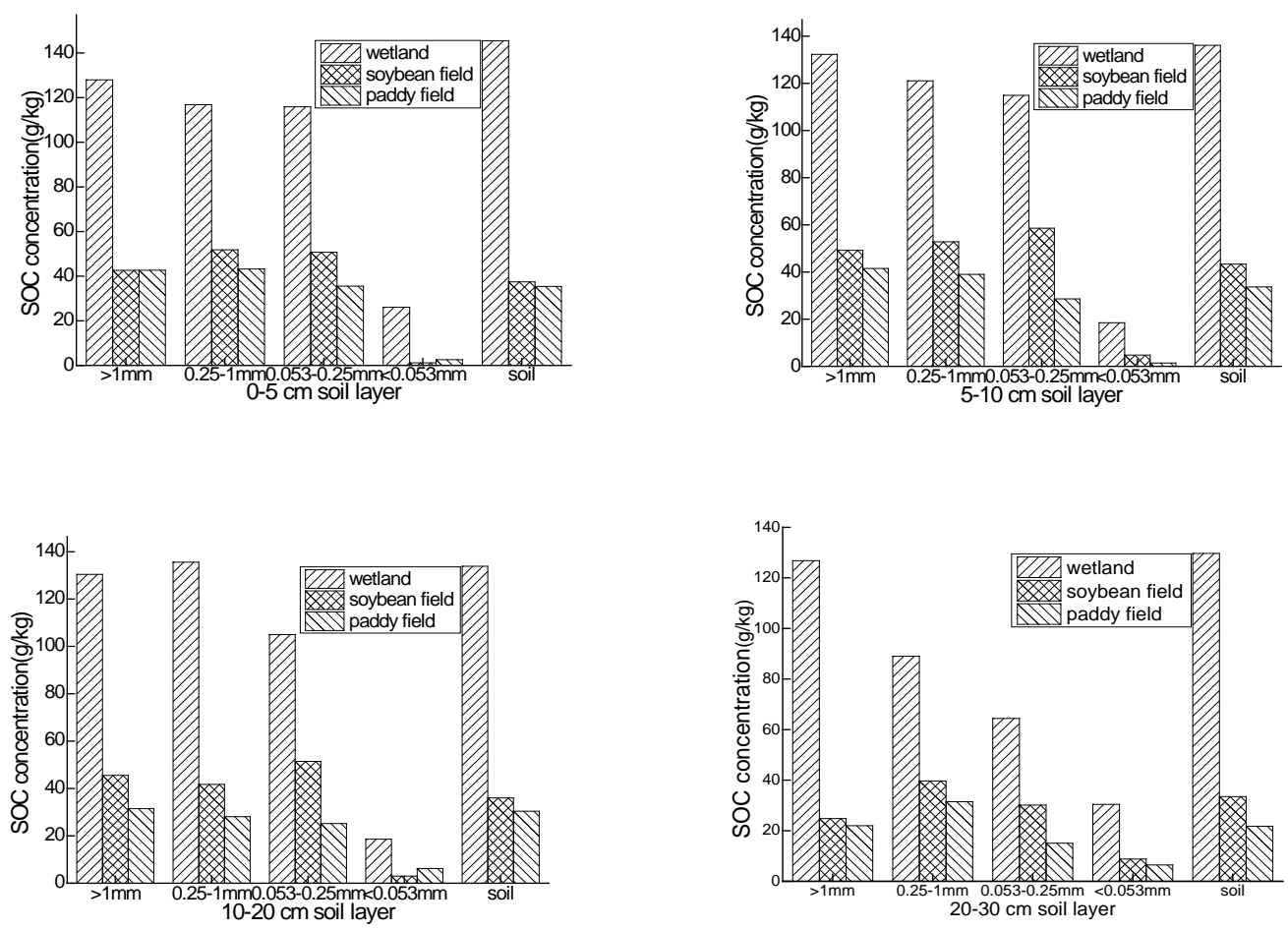

Fig.1 SOC concentration of different aggregates in the soil of wetland, soybean and paddy field

\section{Effect of Wetland Reclamation on the Soc Density of Soil Aggregate and Its Ratio to Soc Density}

The SOC density of soil and different sized aggregates was determined based on ratio of aggregate weight to the total soil, SOC concentration in soil and aggregates, bulk density and soil layer thickness. In 0 30 cm soil layer, the SOC density in soybean and paddy field were $20.3 \%$ and $29.1 \%$ lower than that in wetland, respectively. The SOC density of $<0.25 \mathrm{~mm}$ micro-aggregates was increased at all four soil layers after reclamation with the soybean field exhibiting higher density than paddy field (Fig. 2). The $<0.25 \mathrm{~mm}$ micro-aggregates showed an increase of $349.9 \%, 156.5 \%, 74.5 \%$ and $86.4 \%$ in SOC density in four soil layers in soybean field comparing to wetland, respectively, and the elevation was $132.4 \%, 3.8 \%, 74.1 \%$ and $7.7 \%$ in paddy field, respectively. In addition, the proportion of $<0.25 \mathrm{~mm}$ micro-aggregates SOC density to the soil SOC density was raised in all soil layers due to reclamation. Compared with wetland, the percentage of $<0.25 \mathrm{~mm}$ micro-aggregates SOC density to the soil SOC density in soybean field was increased by $18.5 \%, 11.0 \%, 10.0 \%$ and $21.3 \%$ in four soil layers, respectively, which was $8.0 \%, 1.3 \%, 14.0 \%$ and $12.3 \%$ in four soil layers in 
paddy field, respectively. Except for the layer of 10 20 cm, the ratio was higher for soybean field than rice field in other tested layers.
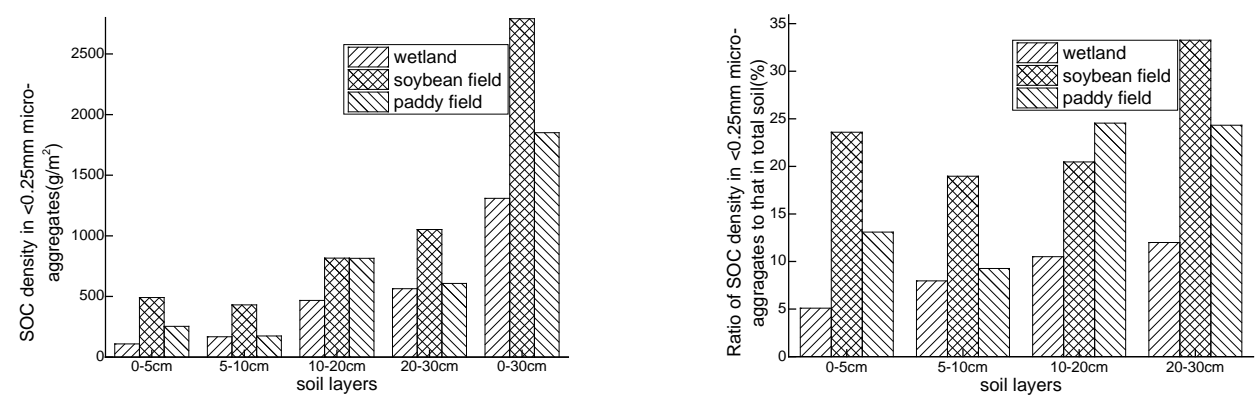

Fig.2 SOC density of $<0.25 \mathrm{~mm}$ micro-aggregates in the soil of wetland, soybean and paddy field and its share in total soil SOC

\section{Discussion}

The content of $>1 \mathrm{~mm}$ macro-aggregates was decreased after reclamation, which might be attributed to the influence of reclamation on the formation condition of large macro-aggregates. The plant residues in the soil are the binding materials for the formation of macro-aggregates. The input of plant residues is significantly reduced upon wetland reclamation, which impedes the development of macro-aggregates [13]. The litter amount of wetland $\left(1230.42 \mathrm{~g} / \mathrm{m}^{2}\right)$ was higher than the sum of the litter $\left(624.17 \mathrm{~g} / \mathrm{m}^{2}\right)$ and root residues $\left(214.61 \mathrm{~g} / \mathrm{m}^{2}\right)$ in soybean field, and it was also higher than the amount of rice stubble $\left(771.56 \mathrm{~g} / \mathrm{m}^{2}\right)$, given that the litter amount of rice was minimal. As only the root stubble was returned to the field, while the straw was excluded, therefore the overall plant residue returned to the field was decreased after reclamation. The reduction of the input organic matters leads to reduced supply of food and energy to soil animals and microorganisms, impairing the increase of their quantity and activity. It causes the reduction in the amount of carbon and nitrogen, the biomass of soil microorganisms, as well as the soil basal respiration, largely affecting the formation of macro-aggregates [13,19]. In addition, the tillage activities also destroy macro-aggregates. Other than the basic plough before planting, the soil was plowed up between ridges in the soybean field at the seedling stage to increase yield, and beating was performed in the rice field before rice transplanting, all of which affected the soil structure.

The effects of different reclamation methods on the aggregate content are varied, and this is closely related to the management practices and plant types. Under the waterlogging condition, a large amount of soluble organic matter can be produced in the paddy soil, and then moves down to the lower soil surface. This process could increase the amount of the binding materials which are beneficial for the formation of macro-aggregates and provide more energy to soil microorganisms. It might help to explain our observation that large $>1 \mathrm{~mm}$ macro-aggregates of rice field was higher than that of the soybean field. The long-term application of inorganic fertilizer after reclamation results in the accumulation of many trace elements, such as Fe and Mn. Using underground water for irrigation leads to the over accumulation of a large amount of $\mathrm{Fe}$ in the topsoil (according to our investigation, the well irrigation practice in Sanjiang Plain induced the Fe content to 100 fold in paddy soil water, most of which were accumulated in the topsoil). The iron-manganese oxides can facilitate the formation of micro-aggregates, with serving as adhesive agent $[13,20]$, therefore the content of micro-aggregates might be increased after wetland reclamation. The increase of $<0.25 \mathrm{~mm}$ micro-aggregate content in the soybean field was higher than that of paddy field. The alternative explanation is that the presence of a great number of arbuscular mycorrhizal fungi and rhizobia in the microecosystem of soybean rhizospheremay favor the development of the unique symbiosis of arbuscular mycorrhizal fungus-soybean-rhizobium [21], while the mycelium also contributes to the formation of micro-aggregates [13,22,23]. 
After wetland reclamation, the soil organic matter sourced from the plant residues was reduced, and the change of the soil hydrothermal condition accelerated the degradation of soil organic matters, which led to the decrease of soil SOC concentration [24]. The SOC concentration in soybean field was higher than that in paddy field. The litter amount (dead leaves and petioles) of soybean field at the end of the growing season was $624.17 \pm 107.97 \mathrm{~g} / \mathrm{m}^{2}$ more than that of paddy field. Although the root stubble of paddy field was $556.95 \pm 59.44 \mathrm{~g} / \mathrm{m}^{2}$ less than that of soybean field after harvesting, the soybean litter and root stubble were more perishable than rice root stubble. Therefore, the undecomposed rice stubble was removed or directly burned to facilitate soil leveling by agricultural machinery in the next year, leading to the higher SOC concentration in soybean field compared to that in paddy field. The distribution pattern of soil SOC in different sized aggregates was in consistent with the observation that wetland was the highest followed by soybean and paddy fields.

For aggregates, the SOC density is determined by ratio of aggregate weight to the total soil, SOC content in aggregates, bulk density and soil layer thickness. The content of micro-aggregate and bulk density were increased upon wetland reclamation, while its SOC concentration was decreased, leading to the elevation of micro-aggregate SOC density. The SOC density of micro-aggregates in soybean field was higher than that in paddy field, which is resulted from the joint outcome of the higher content of micro-aggregate itself and the higher SOC concentration of micro-aggregate in soybean field. After wetland reclamation, the SOC density of micro-aggregate and its proportion to the soil were elevated with more SOC allocated into the $<0.25 \mathrm{~mm}$ micro-aggregate. The SOC density and its percentage to the soil SOC density of paddy field were less than those of soybean field, and no extra SOC was allocated into micro-aggregate for a better protection, differing from that in the soybean field. In 0-30 cm soil layer in the soybean field, the amount of SOC with a strong physical protection by micro-aggregates was greater than that in paddy field; therefore, reclaiming the wetland into soybean field instead of paddy field is more friendly for the long-term retention of SOC.

\section{Conclusions}

After wetland reclamation, the content of $>1 \mathrm{~mm}$ macro-aggregates was reduced, while opposite trend was observed in the $0.25 \sim 1 \mathrm{~mm}$ macro-aggregate and micro-aggregate $(0.053 \sim 0.25 \mathrm{~mm}$ and $<0.053 \mathrm{~mm}$ ). Except for 10 20 cm soil layer, the content of macro-aggregates with sizes of $>1 \mathrm{~mm}$ and $0.25 \sim 1 \mathrm{~mm}$ in the soybean field, were lower and higher than those of paddy field, respectively. Moreover, soybean field showed a higher amount of $<0.25 \mathrm{~mm}$ micro-aggregates than the paddy field in all tested soil depths.

Wetland reclamation reduced the SOC concentration in the soil and different sized soil aggregates, and the SOC concentration was higher in soybean field than in paddy field in all sized aggregates except for those with the size of $<0.053 \mathrm{~mm}$ in the soil layers of $0 \sim 5$ and $10 \sim 20 \mathrm{~cm}$.

The order of the SOC density in $0 \sim 30 \mathrm{~cm}$ soil layer was wetland> soybean field> rice field after reclamation. The SOC density of $<0.25 \mathrm{~mm}$ micro-aggregate and its percentage were both elevated in all tested soil layers $(0 \sim 5,5 \sim 10,10 \sim 20$ and 20 30 cm), which were higher in soybean field than in paddy field. Thus, higher amount of SOC was allocated into $<0.25 \mathrm{~mm}$ micro-aggregates and might be protected better in soybean field than in paddy field, and reclaim the wetland into soybean field instead of paddy field is more beneficial for the long-term retention of SOC.

\section{Acknowledgement}

This paper was supported by the National Natural Science Foundation of China (grant no. 41501102, 41601104), Innovation Project 2017-cxgc-lyj and Science \& Technology Project of Industry (Agriculture) 201403014.We appreciate the assistance in the field work on this study by the Xingkai Lake Wetland Experimental Station, Chinese Academy of Sciences and its staff! 


\section{References}

[1] R. Lal, Soil Carbon sequestration to mitigate climate Change. Geoderma, 123(2004) 1-22.

[2] T. Eglin, P. Ciais and S. L. Piao, Historical and future perspectives of global soil carbon response to climate and land-use changes. Tellus, 62B (2010) 700-718.

[3] R. J. Haynes, Labile organic matter fractions as central components of the quality of agricultural soils: an overview. Advances in Agronomy, 85(2005) 221-268.

[4] E. A. Davidson, I. A. Janssens, Temperature Sensitivity of Soil Carbon Decomposition and Feedbacks to Climate Change. Nature, 440(7081) (2006) 165-173.

[5] M. Von Lützow, I. Kögel-Knabner and K. Ekschmitt, SOM fractionation methods: relevance to functional pools and to stabilization mechanisms. Soil Biology \& Biochemistry, 39(9) (2007) 2183-2207.

[6] K. Budge, J. Leifeld and E. Hiltbrunner, Alpine grassland soils contain large proportion of labile carbon but indicate long turnover times. Biogeosciences, 8(7) (2011) 1911-1923.

[7] M. Q. Liu, F. Hu and X. Y. Chen, A review on mechanisms of soil organic carbon stabilization. Acta Ecologica Sininca, 27(6) (2007) 2642-2650.

[8] B. John, T. Yamashita and B. Ludwig, Storage of organic carbon in aggregate and density fractions of silty soil under different types of land use. Geoderma, 128(1-2) (2005) 63-79.

[9] J. Six, K. Paustian and E. T. Elliott, Soil structure and organic matter: I .distribution of aggregate-size classes and aggregate-associated carbon. Soil Science Society of America Journal, 64(2) (2000) 681-689.

[10] J. S. Xie, Y. S. Yang and G. S. Chen, Effect of vegetation restoration on water stability and organic carbon distribution in aggregates of degraded red soil subtropics of China. Acta Ecologica Sininca, 28(2) (2008) 702-709.

[11] H. X. Liu, Y. H. Yuan and Q. R. Huang, Effect of fertilization on soil organic carbon distribution in various aggregates of red paddy soil. Acta Pedological Sinica, 43(3) (2006) 422-429.

[12] J. Six, R. T. Conant and E. A. Paul, Stabilization mechanisms of soil organic matter: implications for C saturation of soils. Plant and Soil, 241(2) (2002) 155-176.

[13] J. Six, H. Bossuyt and S. Degryze, A history of research on the link between (micro)aggregates, soil biota, and soil organic matter dynamics. Soil \& Tillage Research, 79(1) (2004) 7-31.

[14] M. Nie, E. Pendalla and C. Bellb, Soil aggregate size distribution mediates microbial climate change feedbacks. Soil Biology \& Biochemistry, 68 (2014) 357-365.

[15] Northeast Institute of Geography and Agricultural Ecology, Chinese Academy of Sciences, The Sanjiang Plain wetland, Changchun, China, 1983.

[16] C.C. Song, Y.Y. Wang and B.X. Yan, The changes of the soil hydrothermal condition and the dynamics of C, N afterthe mire tillage. Environmrntal Science, 25(3) (2004), 150-154.

[17] Committee on soil agrochemical Analysis of soil Society of China. Conventional analytical methods of soil agricultural chemistry. Science and Technology Press, Beijing, China,1983, pp.33.

[18] J. G. Bockheim, K. M. Hinkel and F.E. Nelson, Predicting carbon storage in Tundra Soils of Arctic Alaska. Soilence Society of America Journal, 67(3) (2003) 948-950.

[19] L. L. Huo, J.W. Guo and Y. C. Zou, Effect of reclamation on microbial biomass and activity in peat mire soil around Xingkai Lake in northeast China. Fresenius Environmental Bulletin, 2015, 24 (2015) 1098-1107. 
[20] C. C. Muggler, C. Van Griethuysen and P. Buurman, Aggregation, organic matter, and iron oxide morphology in Oxisols from Minas Gerais, Brazil. Soil Science, 164(10) (1999) 759-770.

[21] D. D. Zhao, T. Li and Z. W. Zhao, Research advances in arbuscular mycorrhizal fungi-legumes-rhizobia symbiosis. Chinese Journal of Ecology, 25(3) (2006) 327-333.

[22] Q. Wen, X. Guan, Progress in the study on soil aggregate Formation. Arid Zone Research, 21(4) (2004) 434-438.

[23] J. M. Tisdall, S. E. Smith and P. Rengasamy, Aggregates of soil by fungal hyphae. Australian Journal of Soil Research, 35(1) (1997) 55-60.

[24] Y. Y. Wang, Study on the change of greenhouse gas flux before and after reclamation of Sanjiang plain. Changchun Jilin province, Northeast Institute of Geography and Agricultural Ecology, Chinese Academy of Sciences, 2005. 